\title{
Conceptual Framework for Nurses in the Use of the Neuman Sys- tems Model on Caregivers of People Suffering by Schizophrenia
}

\author{
Kerime Bademli' ${ }^{*}$ and Zekiye Çetinkaya Duman ${ }^{2}$ \\ ${ }^{1}$ Faculty of Nursing, Akdeniz University, Turkey \\ ${ }^{2}$ Faculty of Nursing, Dokuz Eylul University, Turkey
}

*Corresponding author: Kerime Bademli, PhD, Assistant Professor, Faculty of Nursing, Akdeniz University, Turkey, Tel: +90-242-3106910, Fax: +90-242-2261469, E-mail: kerimedemirbas@akdeniz.edu.tr

\begin{abstract}
Nursing knowledge is shaped by nursing conceptual models and nursing theories. Nursing theories and models explain the basic metaparadigm concepts related to nursing discipline and the correlation between these concepts, and focus on the role of nursing. Models bring a point of view on nursing and direct nursing practices. Conceptual models in nursing bring a common meaning to the basic concepts of nursing. It is important to use the nursing model as guideline in the practices. In this study, the philosophical and theoretical basis of the Neuman Systems Model, the model's description, and its use on caregivers of patients with schizophrenia took place. The Neuman Systems model provides the nurse with a conceptual framework and contributes to provide a holistic care while working with caregivers of patients with schizophrenia. The Neuman Systems model provides the nurse with a comprehensive assessment in terms of caregiving and explains how the primary, secondary and tertiary prevention interventions can be used in problem-solving. Using the Neuman Systems Model to help understand the environmental forces that impact the client system will offer nurses insight into the family's coping ability. At this point, the Neuman Systems Model provides nurses with a comprehensive viewpoint regarding how schizophrenia affects caregivers, and helps nurses plan and implement interventions to empower coping of the caregivers of schizophrenic patients.
\end{abstract}

\section{Keywords}

Neuman systems model, Schizophrenia, Family, Caregiver, Coping

The Neuman Systems Model is a suitable model for guiding the nursing studies and practices in terms of offering a systems-based comprehensive conceptual framework and providing a holistic viewpoint [1]. While developing the systems model, Neuman used Gestalt, systems and stress adaptation theories. The Neuman Systems Model has a dynamic structure that provides a systems-based holistic viewpoint and is based on the protection of environmental factors in relation to the system, which is oriented to the state of wellness, and the system balance with regard to these factors [2]. The Neuman Systems Model shows a comprehensive conceptual structure related to stressors, reactions given against stressors and protective interventions. In the model, the system approach is taken as basis and it is explained how the system remains in balance against the stressors. In the Neuman systems model, the patient is considered a system and it is clarified that the system has its lower segments and these segments are interrelated. According to Neuman, a human being is an ever-changing open system that is in mutual interaction with the environment. The Neuman client system may be an individual, a family, a group or a community. The client system is addressed in a holistic manner in the model and is considered as the combination of five variables that affect each other, namely the physical, psychological, socio-cultural, developmental, and spiritual variables $[2,3]$.

Neuman describes a human being as a basic structure surrounded by successive rings as a system. The successive rings in the model constitute the lines of defense. The lines of defense are defined as flexible lines of defense, normal lines of defense, and the lines of

Citation: Bademli K, Duman ZC (2017) Conceptual Framework for Nurses in the Use of the Neuman Systems Model on Caregivers of People Suffering by Schizophrenia. Int Arch Nurs Health Care 3:079. doi.org/10.23937/2469-5823/1510079

Received: July 25, 2017: Accepted: September 18, 2017: Published: September 20, 2017

Copyright: (c) 2017 Bademli K, et al. This is an open-access article distributed under the terms of the Creative Commons Attribution License, which permits unrestricted use, distribution, and reproduction in any medium, provided the original author and source are credited. 
resistance; and each line involves physical, psychological, socio-cultural, developmental and spiritual variables. The basic structure is the main vital factors (normal body temperature, genetics, structure of ego, etc). Flexible line of defense keeps an individual's normal balance, keeps the system away from stressors, and prevents stressors from affecting the client system. The normal line of defense reflects the individual's normal or general state of wellness. It develops as a result of environmental stressors and the individual's previous experiences. When the system is not sufficiently protected by the flexible rings of defense, any stressor may pass through the normal ring of defense and create a reaction in the individual. The lines of resistance are the lines that surround the basic structure of client system. When damaging the normal line of defense, stressors activate and protect the basic structure [2,3].

Neuman defines stressors as the potential warnings which cause the stress that may disrupt the system's balance. Every individual is exposed to various stressors that threaten their system throughout their life [3]. Stress has the potential of creating a disturbance or imbalance in one's harmony and requires an answer. Defense mechanisms respond to stressors in order to prevent them from reaching the central energy source. Life is threatened if defense mechanisms are affected [4]. The lines of defense specified in the Neuman systems model prevent stressors from reaching the basic structure. Many stressors are universal and sometimes stressors disrupt the individual's system and lead to physical illness or emotional and social crises [5]. In this model, family is defined as an open system that includes the subsystem of family members. The family system tries to maintain its state of balance against the effects of internal and external environmental stressors that threaten the state of wellness [3].

In the Neuman systems model a three-dimensional framework of interpersonal, intrapersonal, and extrapersonal stressors is used to analyze the client's stress. Caregiver tasks can be considered as stressors or the source of stress in the caregiving experience. The caregivers' unique perception of whether a task is difficult may make a difference in their caregiving experience. Families both affect and are affected by a mentally ill member through a dynamic process impacting patterns of communication, interactional styles, family responsibilities, and family roles as the family adapts to the physical and psychological demands of managing the illness $[6,7]$. The primary purpose of family is to maintain the integrity of the structure and continue the family's state of wellness [8]. Chronic mental illnesses negatively affect the family's life and lead to stress $[8,9]$. Therefore, difficulties experienced by the caregivers of schizophrenic patients in the process of care-giving create stressor effects.

In the Neuman systems model, the specified lines of defense are related to the methods of coping used by caregivers against stressors. The use of effective coping methods prevents stressors from damaging the individual's defense lines, and thus enables protection of the individual's basic structure. In the circumstances, the determination of the coping methods used by the caregivers of patients with schizophrenia and the use of effective coping methods enable to remain the caregiver's system in balance and therefore may protect the basic structures.

\section{Flexible Line of Defense}

This line constitutes the outer boundary of the defined client system. The flexible line of defense serves as a situational protective buffer system for the individual's normal or stable state. The flexible line of defense protects the client system from the stressor attacks. If the flexible line of defense is not strong enough or the stressors are very strong, entrance to the normal line of defense takes place [3]. The flexible line of defense has an accordion-like function. If this line is expanded beyond the normal line of defense, it provides high protection; if it is close to the normal line of defense, it provides lower levels of protection [2]. For instance, if healthy lifestyles and effective coping mechanisms are used, the individual's flexible line of defense expands. Stressors may invade the client system; however, this line acts as a buffer area against the stressors and protects the individual from the stressors $[3,5]$. In response, a mother mobilizes psychosociocultural factors, for example through help seeking Effective coping methods used by individuals display the buffer effect in reducing the effect of stressors on the individual. In a study conducted that neither family cohesion nor family flexibility exerted significant direct effects on caregivers' psychological distress. Thus, more unbalanced flexibility levels were associated with greater feelings of burden among caregivers, which are related to higher levels of psychological distress [6] 2016. Caregivers of schizophrenic patients use the effective and ineffective coping methods of crying, denial, anger, withdrawal from social life, aggressive behaviors, positive thinking, knowledge acquisition, receiving support from friends and neighbors, and seeking social support together [10-14]. However, it has been reported that the coping strategies of caregivers are insufficient and caregivers are in need of nursing interventions to improve their coping [11]. In a study conducted that caregivers used a wide repertoire of coping behavior to deal with the patient. Problem focused coping was used mainly in dealing with aggressive behavior followed by social support. Avoidance coping was used by few caregivers which is maladaptive in nature and can further stigmatize the mentally ill population [15]. Evaluation of stress management in caregivers, the use of adaptive coping strategies and to identify carers who need additional support with recovery-oriented information about schizophrenia and need to intervention [16]. The use of effective coping methods among care- 
givers of schizophrenic patients may enable to expand the flexible lines of defense and thus to protect one's basic structure. This is why nurse psychoeducation and counseling will serve as an important means to empower caregivers.

\section{Normal Line of Defense}

This is the normal or usual wellness level of the client system. It is defined as the continuity of the individual's dynamic state of balance. First response to stressors is formed in case of entrance to the normal line of defense [3]. The normal line of defense may be used as a standard to measure health deviations [2]. The normal line of defense is a result or combination of the individual's normal coping methods, lifestyle, the phase of development and some similar variables and behaviors. This is one's way of coping with stressors while maintaining their presence in the cultural texture one was born into and tries to adapt to [3].

As caregivers' responsibilities for caregiving to chronic diseases increase, the caretaking-caregiving relation may turn into a one-way, dependent, intense, and long-term difficulty that causes unease for the caregiver. Caregiving causes to undertake the care responsibility of a patient and to play the caregiver role. Playing the caregiver role is a situation that cannot be selected or planned. Therefore, the individual may not be ready for this role change [8,17-19]. Role change is one of the most significant changes that caregivers go through. The caregiver has different obligations such as work, being a mother, being a spouse, etc. When an illness occurs in the family, the patient is in the center of the activities of the person that undertakes the caregiving role. In the circumstances, the caregiver has many needs. It leads to stress for the caregiver if their needs related to the responsibility of caregiving are not met $[20,21]$. Sintayehu, et al. 2015 reported that overall prevalence of mental distress among caregiver $56.7 \%$. The factors social support, two or more times admission of patient, care giving for psychotic patient, were found to be predictors for mental distress of caregivers [22]. Caregivers of schizophrenic patients may encounter with different stressors at different times [23]. In a study conducted by Onwumere, et al. 2017, it is stated that caregivers' beliefs about schizophrenia affect coping style. Caregivers who have a negative attitude towards their patients are affected by the negativity they experience in different areas of their lives. From the perspective of the Neuman Model internal stressors are perception of patient health, preparation for caregiving, confidence in caregiving, and caregiver burden. Using ineffective coping methods to deal with stress may lead to experiencing chronic stress. Once caregivers cannot cope effectively with the difficulties they experience, they feel a burden in social, emotional, economic and physical aspects [24]. External stressors, such as patients health status or caregiving requirements, can weaken the flexible line of defense to threaten the normal line of defense. The caregiver may develop various reac- tions to cope with this stressor and preserve their normal line of defense. When the caregiver's care-giving responsibility is examined as a general stressor, stressors may have invaded the normal line of defense. The caregiver's role conflict means being tired of the role and the invasion of the normal line of defense if the caregiver is going through stress. In the circumstances, if the caregiver's coping is not sufficient, his/her physical and emotional health may be deteriorated [21].

\section{Lines of Resistance}

When the normal line of defense is entered, the lines of resistance are activated; this function of resistance lines is intended for preventing the main response [3]. Their task is to protect the system against stressors and maintain a healthy life. Lines of resistance protect the basic structure and support return to wellness. The line of resistance is the coping methods that the individual learnt in time; if the individual is able to use effective coping methods, the basic structure may be prevented from being affected [2].

Neuman states that nurses should evaluate the possible effects of individuals' internal and external stressors, and enter into the worlds of the individuals by assisting their stabilities and balances. According to Neuman, when a stressor is suspected or diagnosed, the intervention should be initiated. Interventions may take place in both reaction and reconstruction phases before or after the line of resistance is affected. Interventions are based according to their reaction degrees, resources, and expected outcomes [5].

In chronic mental illnesses, the first stress response to caregiving responsibility represents the role conflict, being tired of the role, and attack of caregiving-related stressors to the normal line of defense. Obstacles of receiving information from health personnel, lack of family/friend support, financial concerns, burden, stigmatization, and insufficiency in caregiving are the stressors aiming for the resistance line of caregiver system. The caregiver's concerns regarding their patient's physical and emotional health may affect the basic structure and lead to reactions [21]. Family interventions may be used for empowering the resistance line of caregivers of schizophrenic patient. It is stated that the families of patients with chronic mental illness use insufficient coping strategies to maintain the family's functionality in the caregiving process, and caregivers are in need of effective nursing interventions to improve their coping [16]. The importance of family interventions has recently been emphasized to help families with chronic mental illness effectively cope with the difficulties they experience [23]. Determination of families' needs by healthcare personnel, planning and implementing early interventions, informing families, and executing programs where families can share their difficulties and experiences with each other increase the coping levels of families [25-28]. The core response may be protected 
by empowering the resistance lines among caregivers who use effective coping methods.

\section{Core Response}

The basic structure is made up of primary vital factors specific to species [2]. It includes innate genetic characteristics and survival factors. Characteristics such as the protection mechanism of the body temperature, genetic characteristics, and organ weakness and strength constitute the basic structure [3]. The successive rings, flexible and normal rings of defense, and resistance rings act as the protective mechanism of the basic structure against any attack to integrity [2].

Family members with chronic mental illness experience emotions such as stress, anxiety, depression, embarrassment, guilt, fear, despair, uneasiness, worry, and hopelessness $[29,30]$. The rates of depressive symptoms and anxiety have been found to be higher than the general population as a result of the stress experienced by caregivers [31,32]. In another study, $65 \%$ of caregivers of schizophrenic patients were found to have a high mental disorder risk [11]. According to the results of these studies, stressors disrupted the caregiver system balance in this group and affected the basic structure of caregivers. Caregivers identified concerns for their own physical and emotional health and so there is potential for a core response. Nurses should take primary protection precautions in order to prevent individuals' basic structure from being affected.

If a family member is diagnosed with a chronic mental illness, caregivers are required to initiate taking primary protection precautions. The caregiving system may not be affected if the caregivers are informed on the caregiving roles they will play and the caregiving responsibility they will undertake through family interventions and are taught the ways of coping with the stressors they encounter. Therefore, the caregiver's basic structure may be protected.

If the basic structure in caregivers of the schizophrenic patient is affected, secondary and tertiary prevention precautions should be taken. These families should be determined as high risk families and should be included in intervention programs depending on the diagnosis of their difficulties and strengths and according to their needs [33]. Various family interventions are applied for the caregivers of schizophrenic patients. Family interventions that provide families with information regarding the disease, its treatment and ways of coping with the disease have been reported to be effective in increasing the families' functionalities, helping them cope with the disease, reducing their difficulties, problem-solving, and increasing their capabilities of communicating with the patient $[26,27,34,35]$.

\section{Conclusion}

According to Neuman, nursing is the only profession that examines individuals' responses to stressors in terms of all variables [2]. The Neuman Systems Model is an appropriate model for establishing a holistic approach to- wards the patients and guiding nursing practices since it includes five major variables (physiological, psychological, socio-cultural, spiritual, and developmental) of individuals through its open system properties. In this model, it is explained how the system remains in balance against the stressor by taking the system approach as the basis $[2,3]$. Model considers the client's perceptions of needs and encourages partnership with caregivers to retain, attain, and maintain the wholistic goal of client system optimal wellness. The model is designed to organize and direct care-giving activities with the client as central focus [36]. Neuman system model can be used for defining intra-, inter- and extra-personal stressors in nursing practices. By this means, it provides the nurse with a comprehensive assessment in terms of caregiving and explains how the primary, secondary and tertiary prevention interventions can be used in problem-solving. Using the Neuman Systems Model to help understand the environmental forces that impact the client system will offer nurses insight into the family's coping ability [37].

Consequently, in this study, the theoretical framework of the Neuman Systems Model, the model's suggestions, the effects of schizophrenia on caregivers based on this model, and the effects of the difficulties experienced by caregivers on the caregiver system have been identified. Moreover, this study offers a conceptual framework for nurses in use of the Neuman Systems Model on caregivers of schizophrenic patients. Future studies are required to be conducted on caregivers of schizophrenic patients, by using the Neuman Systems Model as a conceptual framework.

\section{References}

1. Fawcett J, Giangrande SK (2001) Neuman systems model-based research: An integrative review project. Nurs Sci Q 14: 231-238.

2. Fawcett $\mathrm{J}$ (2005) Contemporary nursing knowledge analysis and evaluation of nursing models and theorisee. ( $2^{\text {nd }}$ edn), FA Davis Company, Philadelphia, 166-199.

3. Neuman B, Fawcett $J(2002)$ The Neuman systems model. ( $4^{\text {th }}$ edn), New Jersey, 3-32.

4. McEwen M, Wills EM (2002) Theoretical basis for nursing. (2 $2^{\text {nd }}$ edn), Lippicott Williams ve Wilkins, United States, 368-387.

5. Alligood MR, Tomey AM (2006) Nursing theory: Utilization and application. ( $3^{\text {rd }}$ edn), St. Louis, Mosby/Elsevier, MO.

6. Koutra K, Simos P, Triliva S, Lionis C, Vgontzas AN (2016) Linking family cohesion and flexibility with expressed emotion, family burden and psychological distress in caregivers of patients with psychosis: A path analytic model. Psychiatry Res 240: 66-75.

7. Kaakinen JR, Hanson HMS (2004) Theoretical foundation for family health nursing practice. Promoting Health in Families. Elsevier Inc, United States.

8. Stanley S, Balakrishnan S, llangovan S (2017) Psychological distress, perceived burden and quality of life in caregivers of persons with schizophrenia. J Ment Health 26: 134-141.

9. Hu C, Kung S, Rummans TA, Clark MM, Lapid MI (2015) 
Reducing caregiver stress with internet-based interventions: A systematic review of open-label and randomized controlled trials. J Am Med Inform Assoc 22: e194-e209.

10. Sheikholeslami F, Khalatbary J, Ghorbanshiroudi S (2016) Effectiveness of stress coping skills training with psycho-educational approach among caregivers of schizophrenic patients on family function and psychological wellbeing. $J$ Holist Nurs Midwifery 26: 46-54.

11. Inan FŞ, Duman ZÇ (2013) Şizofreni hastasına bakım verenlerin ruh sağlığını etkileyen faktörler: sosyodemografik değişkenler ve stresle başa çıkma tarzları. J Anatolia Nurs Health Sci 16: 205-211.

12. Malla AA, Bhat NM, Wagay ZA (2015) A study of coping styles and stress tolerance in the caregivers of schizophrenic patients. The International Journal of Indian Psychology 3: 41-48.

13. Lam PC, Ng P, Pan J, Young DK (2015) Ways of coping of Chinese caregivers for family members with schizophrenia in two metropolitan cities: Guangzhou and Hong Kong, China. Int J Soc Psychiatry 61: 591-599.

14. Nehra R, Chakrabarti S, Kulhara P, Sharma R (2005) Caregiver coping in bipolar disorder and schizophrenia--a re-examination. Soc Psychiatry Psychiatr Epidemiol 40: 329-336.

15. Varghese A, Khakha DC, Chadda RK (2016) Pattern and type of aggressive behavior in patients with severe mental illness as perceived by the caregivers and the coping strategies used by them in a tertiary care hospital. Arch Psychiatr Nurs 30: 62-69.

16. Onwumere J, Lotey G, Schulz J, James G, Afsharzadegan $R$, et al. (2017) Burnout in early course psychosis caregivers: The role of illness beliefs and coping styles. Early Interv Psychiatry 11: 237-243.

17. Chien WT (2008) Effectiveness of psychoeducation and mutual support group program for family caregivers of chinese people with schizophrenia. Open Nurs J 2: 28-39.

18. Quah S (2014) Caring for persons with schizophrenia at home: examining the link between family caregivers' role distress and quality of life. Sociol Health IIIn 36: 596-612.

19. Atagün Mi, Balaban ÖD Atagün Z, Elagöz M, Özpolat AY (2011) Kronik hastalıklarda bakım veren yükü. Psikiyatride Güncel Yaklaşımlar 3: 513-552.

20. Decter SD, Young E (1991) Self perceived needs of primary caregivers of home hospice clients. $\mathrm{J}$ Community Health Nurs 8: 147-154.

21. Skalski CA, DiGerolama L, Gigliotti E (2006) Stressors in five client populations: Neuman systems model-based literature review. J Adv Nurs 56: 69-78.

22. Sintayehu M, Mulat $H$, Yohannis $Z$, Adera T, Fekade M (2015) Prevalence of mental distress and associated factors among caregivers of patients with severe mental illness in the outpatient unit of Amanuel Hospital, Addis Ababa, Ethiopia, 2013: Cross-sectional study. J Mol Psychiatry 3: 9.
23. Ran MS, Chan LW, Ng SM, Guo LT, Xiang MZ (2015) The effectiveness of psychoeducational family intervention for patients with schizophrenia in a 14-year follow-up study in a Chinese rural area. Psychol Med 45: 2197-2204.

24. Schulze B, Rössler W (2006) Ruhsal hastalıkta bakım verenin yükü: 2004-2005'te ölçümler, bulgular ve müdahalelerin gözden geçirilmesi. Curr Opin Psychiatry 2: 47-58.

25. Girón $M$, Nova-Fernández F, Mañá Alvarenga $S$, Nolasco A, Molina-Habas A, et al. (2015) How does family intervention improve the outcome of people with schizophrenia? Soc Psychiatry Psychiatr Epidemiol 50: 379-387.

26. Bademli K, Duman ZÇ (2014) Effects of a family-to-family support program on the mental health and coping strategies of caregivers of adults with mental illness: A randomized controlled study. Arch Psychiatr Nurs 28: 392-398.

27. Glynn SM, Cohen AN, Dixon LB, Niv N (2006) The potential impact of the recovery movement on family interventions for schizophrenia: Opportunities and obstacles. Schizophr Bull 32: 451-463.

28. Magliano L, Fadden G, Madianos M, de Almeida JM, Held $T$, et al. (1998) Burden on the families of patients with schizophrenia: Result of the BIOMED I study. Soc Psychiatry Psychiatr Epidemiol 33: 405-412.

29. Saunders JC, Byrne MM (2002) A thematic analysis of families living with schizophrenia. Arch Psychiatr Nurs 16: 217-223.

30. Gülseren L (2002) Şizofreni ve aile: Güçlükler, yükler, duygular, gereksinimler. Türk Psikiyatri Dergisi 13: 143-151.

31. Thunyadee C, Sitthimongkol Y, Sangon S, Chai-Aroon T, Hegadoren KM (2015) Predictors of depressive symptoms and physical health in caregivers of individuals with schizophrenia. Nurs Health Sci 17: 412-419.

32. Magana SM, Garcia JIM, Hernandez MG, Cortez R (2007) Psychological distress among latino family caregivers of adults with schizophrenia: The roles of burden and stigma. Psychiatr Serv 58: 378-384.

33. Okpokoro U, Adams CE, Sampson S (2014) Family intervention (brief) for schizophrenia. Cochrane Database Syst Rev.

34. Bademli K, Duman ZÇ (2011) Family to family support programs for the caregivers of schizophrenia patients: A systematic review. Turk Psikiyatri Derg 22: 255-265.

35. Bauml J, Froböse T, Kramer S, Rentrop M, Pitschel-Walz G (2006) Psychoeducation: A basic psychotherapeutic intervention for patients with schizophrenia and their families. Schizophr Bull 32: S1-S9.

36. Neuman B, Reed KS (2007) A Neuman systems model perspective on nursing in 2050. Nurs Sci Q 20: 111-113.

37. Eaton PM, Davis BL, Hammond PV, Condon EH, McGee ZT (2011) Coping strategies of family members of hospitalized psychiatric patients. Nurs Res Prac 2011: 392705. 